https://doi.org/10.31470/2706-7904-2020-15-39-43

\title{
LANGUAGE USE OF PATIENTS WITH SCHIZOPHRENIA: AN ANALYSIS OF SENTENTIAL NEGATION
}

\section{Використання мови пацієнтів із шизофренією: аналіз речень заперечення}

\author{
Ayşegül Özcan Vural \\ Ph.D. in Linguistics, Lecturer \\ Dokuz Eylül University (Turkey) \\ aysegul.ozcan@deu.edu.tr \\ https://orcid.org/0000-0002-8711-8399
}

\section{Gülmira Kuruoğlu}

Ph.D. in Linguistics, Professor

Dokuz Eylül University (Turkey)

gulmira.kuruoğlu@,deu.edu.tr

https://orcid.org/0000-0002-4172-0253

\begin{abstract}
Since the first descriptions of schizophrenia, language disturbances have been referred to as formal thought disorder (Boer et. al, 2020). Within this context in this study we analyzed sentential negation in the speech of the patients with schizoprenia to find out whether psychopathology and thought disorders of the patients affect the language use. 50 patients with schizophrenia and 50 healthy subjects were included into the study. The results showed negative and affirmative sentences used by the patients were significantly different from the control group. We hypothesized that psychopathology of the patients with schizophrenia plays a central role in language use. At the end of the study patients were concluded to reflect their negative thoughts in thier speech and use more negative sentences.
\end{abstract}

Key words: schizophrenia, language disorders, sentential negation, affirmative sentence, negative sentence.

\section{Introduction}

The schizophrenics' language is considered pathological and the pathological character of schizophrenics' verbal expression arises from disturbed manner of thinking. Chaotic and incoherent verbal production in schizophrenia is senseless and 
incomprehensible (Wrobel, 1990). Cutting (1985) states despite some experimental evidence of a change in the perception or expression of the prosodic of phonemes, abnormalities are not marked in schizophrenic speech in the phonemic level, but of the syntactic level Özcan and Kuruoğlu (2017) state that patients with schizophrenia use simple sentences more than complex sentences. Besides, the speech patterns used by schizophrenia patients are different in terms of sentence length, and they prefer short and less complicated sentences in communication as a result of their cognitive disorders, including impairment to their attention and abstract thinking abilities (Özcan \& Kuruoğlu, 2018). Of the semantic level, Cutting states that the semantic component of schizophrenic language is not obviously distracted in the large majority of patients, but referring to pragmatics he states the patients with schizophrenia fail to understand the meaning of words in context, cannot communicate their intended meaning to others, produce insufficient internal cohesion in their own speech, do not ensure the listener's needs and talk irrelevantly rather than incompetently (Wrobel, 1990). In addition to the problems in linguistic level, its complex psychopathology includes changes in thought and perception - delusions and hallucinations. Along with personal distress, this detachment from 'reality' (psychosis) brings complexity to the patients (Thompson \& McCabe, 2016). Taking into consideration the linguistic approach and psychopathology in schizophrenia, the aim of this study is to compare sentential negation in the speech of the patients with schizoprenia and healthy subjects and find out whether the psychopathology of the patients affect the language use.

\section{Methods and Techniques of the Research}

50 patients diagnosed with schizophrenia according to DSM-IV and 50 healthy subjects matched with age, gender and educational level participated in the study. The number of subjects in the study was determined using power analysis. The control group did not have a neurological or psychiatric discomfort story. It was defined as the criteria for participation in the study for control group who did not have a progressive central nervous system disease (Alzheimer's, Parkinsonism, etc.), psychiatric disorder, sensory problems (visual problems, neglect, hearing problems, etc.), a history of a stroke or brain disorder (tumor, head trauma, etc.), substance abuse, language, speech or learning problem story, drug use known to affect cognition. All participants mother tongue was Turkish and volunteering for participation in the research was defined as the criteria for participation for control group. While collecting the data, participants were obtained permission about their voluntarily participation in the study and acceptance of the voice recording.

During the application, each patient was interviewed individually in the psychologist's office. The room where the tests were performed was quiet so as not to 
distract the patients' attention. After patients' data collection, all tests were applied to the control group and subjects' speech in the tests was recorded via a voice recorder, and the recordings were transcribed.

In order to compare the rate of sentential negation of schizophrenia patients and control group semi-structured speech test and free speech test were used, and each subject was interviewed for about 15 minutes. The reason for using the two tests was to prevent the tests from affecting the results. Whereas the first verbal test guided the subjects with a question, the second one was related to a free speech and the subjects talked whatever they wanted. In the first verbal test, subjects were asked what they thought about the situation of their country in recent years while in the second verbal test without any guidance, they were tested on whether they could talk about anything that they wanted. Thereafter, the resulting responses were evaluated. The findings obtained after statistical analysis were interpreted linguistically and discussed in the light of relevant literature.

\section{Results}

Sentential negation was analyzed with median and chi square tests. The median test was used to test whether the patients with schizophrenia and control group differ in sentential negation, and the Chi-Square test was used to examine the differences between negative and affirmative sentence count in the same population. Table 2 shows the related results.

Table 2. Chi-square and Median Test Findings on Sentential Negation

\begin{tabular}{|l|l|c|c|c|c|}
\hline & & $\begin{array}{c}\text { Sentence } \\
\text { Count -Sch }\end{array}$ & $\begin{array}{c}\text { Sentence } \\
\text { Count- } \\
\text { Control }\end{array}$ & $\begin{array}{c}\text { Median } \\
\text { p value }\end{array}$ & $\begin{array}{c}\text { chi-square } \\
\text { p value }\end{array}$ \\
\hline $\begin{array}{l}\text { Semi- } \\
\text { structured } \\
\text { Speech Test }\end{array}$ & Affirmative & 342 & 367 & 0.003 & \\
\cline { 2 - 7 } & Negative & 116 & 85 & 0.045 & 0.046 \\
\hline $\begin{array}{l}\text { Free Speech } \\
\text { Test }\end{array}$ & Affirmative & 433 & 553 & 0.046 & \\
\cline { 2 - 7 } & Negative & 68 & 42 & 0.029 & 0.031 \\
\hline
\end{tabular}

As seen in Table 2 in Semi-structured Speech Test, significant correlation was found between the schizophrenia and the sentential negation $(\mathrm{p}<0.005)$. Median test was consistent with chi-square test and it revealed that there was significant difference between the schizophrenia patients and the control group in terms of sentential negation $(\mathrm{p}<0.005)$. According to the results negative sentences used by schizophrenia patients were significantly more than control group. Similarly, in Free Speech Test, a significant 
correlation was found between the disease and sentential negation $(\mathrm{p}<0.005)$. Schizophrenia affected affirmative and negative sentence use in this test and according to the results of the median test, there was again a significant difference between the schizophrenia patients and the control group in negation use $(\mathrm{p}<0.005)$. The results revealed that schizophrenia patients used less affirmative and more negative sentences than control group.

\section{Conclusions}

In this study, affirmative and negative sentences produced by schizophrenia patients and control group in their speech were compared. In both tests, the number of affirmative sentences used by schizophrenia patients was less than the number of positive sentences used by the control group, and the number of negative sentences was more. It is thought that the patients' excessive use of negative sentences is associated with their ability to negatively attribute to the events and emotions they and others experience.

Wunderink and Kaymaz (2002) stated that the most common features of the pressure and delay of thought and action, pessimism, not enjoying anything, fatigue, indecision, uselessness and negative symptoms are the feeling of emptiness, passivity and emotionality. In addition, fear attacks, panic, social phobia are common symptoms in patients with schizophrenia. In this context, mental state of the patients also redounded up their linguistic characteristics. Patients often had negative and questioning thoughts.

Likewise, Brown (1973) states that schizophrenics experience the world in a different way. Their understanding of the world is reflected in semantics. Unfortunately, this understanding is faulty in schizophrenia. As a consequence, the key problem with schizophrenic language lies in thought disorder (Wrobel, 1989).

Matulis (1977), also states speech patterns in schizophrenia are eccentric and difficult to understand; utterances are disconnected, irrelevant, illogical and stereotyped; speech is full of abstractions. In speech there are more objects than subjects and more verbs than adjectives; and also mutism, negativism, delusions and absence of need to communicate with the environment are observed. Metaphors, neologisms, perseverations, echolalia, paralogia and long chains of associations, sometimes totally irrelevant sentences are also seen. On the other hand, the use of passive voice or passive-like structure: I am being..., Things are happening to me...; verbs denoting comprehension and negation: I don't know..., I don't believe...; general references: People say..., They watch...; sentences beginning with impersonal constructions: There is..., There are..., are identified in schizophrenia (Matulis 1977).

The results obtained in our study support these symptoms. In this study Schizophrenia patients used significantly more negative statements than the control group in the tests. The control group used more positive statements than schizophrenia patients in 
both tests. Findings prove that the pessimistic and negative thoughts of schizophrenia patients are associated with the language.

\section{References}

Cutting, J. (1985). The Psychology of Schizophrenia. Edinburgh, London, Melbourne, New York: Churchill Livingstone.

De Boer, J.N., van Hoogdalem, M., Mandl, R.C.W., Brummelman, J., Voppel, A.E., Begemann, M.J.H., \& Sommer, I.E.C. (2020). Language in schizophrenia: relation with diagnosis, symptomatology and white matter tracts. NPJ Schizophrenia, 6(1), 1-10. https://doi.org/10.1038/s41537-020-0099-3

Matulis, A.C. (1977). Language... a Hope. An Introduction to Metaglossotherapy. Detroit: National Research Institute for Psychoanalysis and Psychology.

Ozcan, A., \& Kuruoglu, G. (2018). Sentence length of Turkish patients with schizophrenia. International Journal of Psycho-Educational Research Reviews, 7(1), 68-73.

Ozcan, A., Kuruoglu, G., Alptekin, K., \& Ozsoy, S. (2016). An analysis of complex sentence structures in patients with schizophrenia. Global Journal of Foreign Language Teaching, 6(4), 228-235. https://doi.org/10.18844/gjflt.v6i4.1675

Thompson, L., \& McCabe, R. (2016). 'Good'communication in schizophrenia: a conversation analytic definition. In: O’Reilly M., Lester J.N. (Eds), Palgrave Handbook of Adult Mental Health (pp. 394-418). Palgrave Macmillan, London. https://doi.org/10.1057/9781137496850_21

Wrobel, J. (1989). Language and schizophrenia. John Benjamins Publishing. https://doi.org/10.1075/1lsee.33 